This is the postprint version of the following article: Serna S, Ercibengoa M, Marimón JM, Reichardt N. Measuring Bacterial Glycosyl Hydrolase Activity with a Soluble Capture Probe by Mass Spectrometry. Analytical Chemistry. 2018;90(21):12536-12543. doi: 10.1021/acs.analchem.8b02434. This article may be used for non-commercial purposes in accordance with ACS Terms and Conditions for SelfArchiving. 


\title{
Measuring bacterial glycosyl hydrolase activity with a soluble capture probe by mass spectrometry
}

\author{
Sonia Serna, ${ }^{a}$ María Ercibengoa, ${ }^{\text {b,c }}$ Jose María Marimón, ${ }^{\text {b,c }}$ Niels-Christian Reichardt ${ }^{\mathrm{a}, \mathrm{d} *}$ \\ ${ }^{a}$ CIC biomaGUNE, Glycotechnology Laboratory, Paseo Miramón 182, 20014 San Sebastian, Spain. \\ ${ }^{\mathrm{b}}$ Hospital Universitario Donostia- Instituto de Investigación Sanitaria Biodonostia, Begiristain Doktorea Pasealekua 109, \\ 20014 San Sebastián, Spain \\ ${ }^{\mathrm{c}}$ Biomedical Research Center Network for Respiratory Diseases (CIBERES), ISCIII, 28029 Madrid, Spain \\ ${ }^{d}$ CIBER-BBN, Paseo Miramón 182, 20014 San Sebastian, Spain.
}

\begin{abstract}
A solution phase enzymatic assay has been developed to track bacterial glycosyl hydrolase activity by surface assisted MALDI-TOF mass spectrometry. Lactose was equipped with an azide functionalized linker and was supplemented to bacterial cultures as an artificial substrate for bacterial $\beta$-galactosidase enzyme. The azide linked glycoside probe was then covalently captured on an alkyne functionalized indium tin oxide sample plate via a bio-orthogonal copper catalyzed azide alkyne cycloaddition (CuAAC). The non-covalent immobilization of the alkyne capture tag via hydrophobic interactions on the ITO-sample plate allowed the analysis of the probe conjugate by surface based mass spectrometry. The ratio of digested to non-digested lactose probe was then employed as a measure for bacterial hydrolase activity, which correlated well with bacterial growth measured by optical density. In addition, we established in a proof of concept experiment that the setup was well suited to identify antibiotic susceptibility of bacterial strains with a performance comparable to current state of the art methods. While the proof of concept version is limited to the identification of a single enzyme activity, we envisage that the use of multiple substrate probes in a multiplexed version will allow the quantification of various glycosyl hydrolase activities with clinical relevance in a single experiment.
\end{abstract}

Many heterotrophic bacteria feed on complex plant, fungal or animal glycans as a major energy and carbon source. Particularly gut bacteria have developed highly specific and very efficient polysaccharide degrading capabilities that allow them to break down dietary and host glycans into monosaccharides which are then absorbed through the bacterial cell wall and fermented. The importance of carbohydrates for the gut bacterial metabolism is reflected by the high number of bacterial genes encoding Carbohydrate active enzymes (CAZymes). While only around 17 out of 97 glycosyl hydrolases (GHs) of the human genome have been assigned to nutrient breakdown, glycosyl hydrolase activity is far more common in gut bacteria and a single bacterial organism can encode as many as 260 enzymes alone. Glycosyl hydrolase activities are often shared among species occupying the same major host environments like gut, airways, oral, urogenital tract or skin. Improved functional assays to assign or confirm the activities of the myriad of CAZymes in a rapid manner are still in great demand. ${ }^{1}$

As many gut bacteria can metabolize similar oligo- and polysaccharides, we hypothesized that measuring the activity of saccharolytic enzymes by mass spectrometry could become a practical method for detecting bacterial growth altogether and might eventually become the basis of a novel antibiotic susceptibility assay. In addition, the detection of a particular hydrolytic activity could aid in the classification and identification of bacteria in complex mixtures. The detection of bacterial pathogens is of great importance in the diagnosis and management of human infectious diseases, in veterinary medicine and in many other fields as water and food quality control and the development of rapid, selective and sensitive detection methods is increasingly necessary. Traditionally microbial identification has been based on the cultivation of the bacterial isolates and their subsequent characterization through a panel of biochemical tests, a procedure that can takes at least one day to deliver unambiguous results. To meet the demands for more rapid detection and portability especially in point of care environments and in food pathogen testing a large number of nucleic acid and immune based assays have been developed. ${ }^{2}$ In many centralised clinical microbiology laboratories, however, the majority of microbial pathogens are nowadays identified by profiling their ribosomal proteins by MALDI-TOF MS, a methodology that has both increased speed and throughput over traditional methods. In addition, MALDI-TOF MS has also been employed to detect selected antibiotic resistance mechanisms e.g by measuring $\beta$-lactamases and carbapenemase activity, ${ }^{3}$ showing the potential of MALDI-TOF mass spectrometers for additional analytical tasks in clinical microbiology.

Due to the emergence of antibiotic resistance in many hospital pathogenic bacteria, additional information related to the antibiotic susceptibility is essential for an appropriate infection treatment. ${ }^{4}$ Conventional antimicrobial resistance assays, that need bacterial pathogens to be first isolated from the specimens by culture, are based in the detection of bacterial growth in the presence of the antibiotics tested, whether in solid agar (disk diffusion, agar-dilution, E-test) of liquid media (microdilution) and are recommended to be incubated for $18 \pm 2$ hours. ${ }^{5}$ Other culturebased or phenotypic methods that detect resistant bacteria directly from the specimen use differential or selective culture media containing a specific antibiotic in a unique concentration equivalent to the resistant breakpoint for detecting resistance. This antibiotic-containing plate method can detect resistance due to a wide variety of mechanisms but only to one antibiotic and after incubation for 18-24 hours. 
A

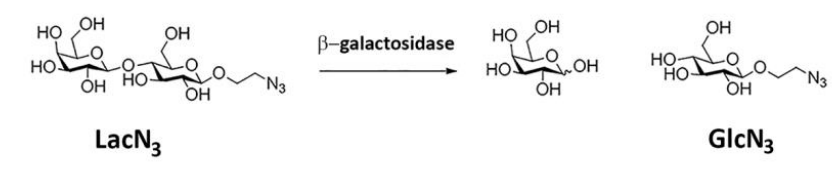

C
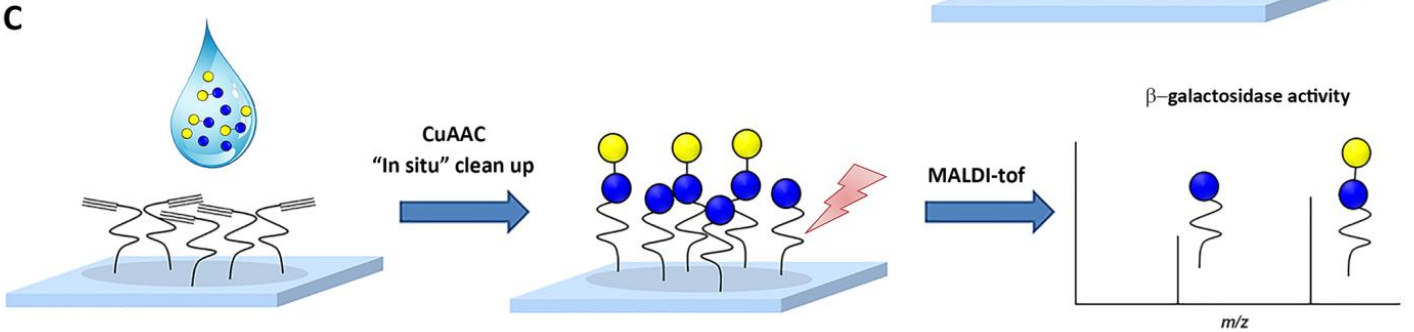

\section{I: :}

Figure 1. A. Hydrolysis of 2 -azidoethyl lactose by the action of $\beta$-galactosidase enzyme. B. Alkyne modified ITO slide C. Schematic representation of the MALDI-TOF analysis of $\beta$-galactosidase activity through immobilization of azido sugars on alkyne modified ITO slides via copper(I)-catalyzed azide-alkyne cycloaddition (CuAAC).

On the other hand, molecular-based or genotypic techniques are more rapid and can detect the determinants of resistance (genes of resistance, mutations, etc.) known for a given species in around 2 to 4 hours. Current methodologies developed for the rapid genotypic detection of antimicrobial-resistant bacteria directly from clinical specimens are generally focused to detect resistance of a single species to a single antibiotic: methicillin-resistant Staphylococcus aureus, carbapenem-resistant Klebsiella etc. However, the presence of these determinants of resistance does not always imply expression of such resistance and these genotypic approaches will not detect resistant isolates with unknown or nontargeted resistance genes. The quantification of bacterial growth either by turbidimetric methods or as a function of enzymatic turnover (e.g. linked to bacterial carbohydrate processing enzymes) remain a major detection methods in antibiotic susceptibility tests for bacteria isolated in culture. These assays often employ carbohydrate substrates with a chromogenic or fluorogenic aglycon that can be detected after enzymatic hydrolysis by optical methods in the culture media and the bacterial growth is then correlated to the enzymatic activity as a function of time. In this scenario, different medium supplements such as yeast or beef extracts, protein hydrolysates or blood can alter light transmission/emission leading to erroneous signal readout. ${ }^{6}$ Mass spectrometry based assays usually require some sort of sample preparation step to remove salts and matrix constituents that could suppress analyte ion formation.To overcome these limitations several laboratories have developed surface-based approaches for the detection of enzymatic activity of purified enzymes and in complex matrices by mass spectrometry. ${ }^{7,8,9,10}$ Immobilization of the substrate to a surface allows including a washing step into the mass spectrometric analysis which reduces ion suppression and spectral interference from background ions of the complex mixture or biofluid. ${ }^{10}$ Glycan substrates have been attached covalently via cleavable thioether linkers to conductive MALDI-compatible gold slides ${ }^{11}$ or non-covalently via fluorous ${ }^{12}$ or hydrophobic interactions onto conductive indium tin oxide ${ }^{10}$ or gold surfaces. ${ }^{8}$
These glycan functionalized surfaces were then employed for the mass spectrometric detection of glycosidase activity on purified enzymes or protein extracts from environmental microbial communities. ${ }^{8,9}$ A general drawback of many surface based assays is their inherently lower sensitivity compared to solution phase assays due to the slower enzyme kinetics on solid-supported substrates. ${ }^{12}$ This can be partly overcome by reducing the substrate surface density but at the cost of also reducing the overall signal strength due to lower substrate concentration. ${ }^{13}$

Reindl et al. employed polysaccharide fragments functionalized with a perfluorinated linker as substrates in solution based assays to detect secreted microbial glycosidase activity. ${ }^{14}$ The perfluorinated amphiphilic glycoconjugates formed colloidal water soluble suspensions which allowed the reactions to be carried out in solution and under more closely controlled conditions. After incubation with microbial enzyme extracts the reaction crudes were placed on perfluorinated sample plates, washed and analyzed by mass spectrometry. ${ }^{14}$ The analysis of enzymatic activity is limited to secreted glycosidases or bacterial lysates ${ }^{15}$ while the activity of intracellular microbial glycosidases is not captured. Moreover, the authors point out that the use of larger glycan fragments is likely to render the tags insoluble.

More recently Yang et al. described a proof of concept MALDITOF MS based $\alpha$-glucosidase assay that employed a hydrazine functionalized perfluorinated tag for the capture of maltose via their reducing end aldehyde function and subsequent immobilization on a fluorinated surface via fluorous interactions to remove non-bound material. ${ }^{16}$ A potential limitation of the method is the lack of selectivity for a particular target glycan as all carbohydrates with a free reducing end present in the sample will react with the hydrazine probe. In addition, the chemoselectivity of the reaction in a more complex sample environment and the stability of the formed hydrazones were not established.

For our objective to detect bacterial growth by mass spectrometry, we required a water soluble probe that could cross the bacterial membrane, act as an artificial substrate for the cytoplasmic $\beta$ - 
galactosidase, and later react chemo-selectively with a capture surface in the presence of any potentially interfering metabolites, proteins or salts. Initial studies had shown that for bacterial growth on sample plates functionalized with fragments of plant oligosaccharides no measurable glycosidase activity could be recorded perhaps because relevant hydrolases were not secreted or only expressed in very low concentration in the absence of inductive growth media. A soluble probe added to the growth medium combined with surface assisted mass spectrometry detection ${ }^{17}$ would avoid these problems and reduce the complexity of the method. We present here a small soluble azide linked lactose probe and a complementary conductive alkyne functionalized sample plate for rapid probe capture via a bioorthogonal "click chemistry" type reaction (Figure 1) and the application of the method in a mass spectrometry-based assay for the detection of glycosidase activity.

For the selective capture of probes from complex environment, we chose the $\mathrm{Cu}(\mathrm{I})$ catalyzed 1,3-dipolar cycloaddition between azide and alkyne moieties to form 1,4-disubstituted triazoles $(\mathrm{CuAAc})$, a reaction that is fast, high yielding, irreversible and can be performed in aqueous media at room temperature. These features have allowed its application in the modification of biomolecules ${ }^{18}$ and in advanced surface modification. ${ }^{19,20}$ Based on our previous development of glycan arrays with dual readout options, we chose indium tin oxide (ITO) coated glass slides as sample plates as this material combines both good conductivity required for the analysis by mass spectrometry with high transparency for the potential readout by fluorescence. ${ }^{10}$ In our proof of concept assay, we chose lactose functionalized with an azido ethyl linker $\left(\mathrm{LacN}_{3}\right)$ as the carbohydrate probe for detecting $\beta$ galactosidase activity. $\beta$-galactosidase enzyme [EC 3.2.1.23] cleaves lactose into galactose and glucose and forms part of the carbohydrate degrading metabolism of bacteria, plants and animals. It is also widely employed in the food industry for processing of lactose $\mathrm{e}^{21}$ and in molecular biology as a gene reporter to measure transfection efficiencies in cells and tissues. ${ }^{22}$ The synthesis of azide modified carbohydrates and their use in click chemistry reactions ${ }^{23}$ for the preparation of neoglycoconjugates, ${ }^{24}$ glycodendrimers $^{25}$ or carbohydrate microarrays ${ }^{26,27}$ has been described previously.

\section{EXPERIMENTAL SECTION}

General methods. Chemicals of analytical grade were purchased from Sigma-Aldrich or Acros Organics and were used without purification. Solvents employed were of HPLC quality. NanopureTM water produced from a Diamond UV water purification system (Branstead International, IA, Madrid, Spain) was employed in the preparation of buffers and aqueous solutions. Indium tin oxide (ITO) coated slides $(75 \mathrm{~mm}$ x $25 \mathrm{~mm}$ ) were purchased from Hudson Surface Technology, Inc. (Fort Lee, NJ). The slides have a nominal transmittance of $>78 \%$ and an ITO thickness of $130 \mathrm{~nm}$. Azidoethyl $\beta$-D-galactopyranosyl-(1,4)- $\beta$-Dglucopyranoside was prepared as previously described. ${ }^{28}$ Stock solution $(40 \mathrm{mM})$ in water was prepared and filtered $(0.2 \mu \mathrm{m})$ under sterile conditions. This solution was used as stock to prepare dilutions to spot on top of alkyne modified surfaces, in enzymatic reactions and as supplement in bacterial cultures. $\beta$ galactosidase from Aspergillus oryzae and from Escherichia coli were purchased from Sigma-Aldrich. Nuclear Magnetic Resonance experiments were acquired on a Bruker $500 \mathrm{MHz}$ spectrometer and chemical shifts $(\delta)$ are given in ppm relative to the residual signal of the solvent used $\left(\mathrm{CDCl}_{3} 7.26 \mathrm{ppm}\right.$ for ${ }^{1} \mathrm{H}-\mathrm{NMR}$, $77.00 \mathrm{ppm}$ for $\left.{ }^{13} \mathrm{C}-\mathrm{NMR}\right)$. Contact angle measurements were performed at room temperature using DSA 100 contact angle meter (Kruss). MALDI-TOF mass analyses were performed on an Ultraflextreme III time-of-flight mass spectrometer equipped with a pulsed Nd:YAG laser $(355 \mathrm{~nm})$ and controlled by FlexControl 3.3 and FlexImaging 2.1 softwares (Bruker Daltonics, Bremen, Germany). The acquisitions (total of 2000-3000) were carried out in positive reflector ion mode with pulse duration of $50 \mathrm{~ns}$, laser fluence of $40 \%$ and laser frequency of $500 \mathrm{~Hz}$. Laser intensity was set marginally above the threshold of ionization to avoid fragmentation (less than $10 \%$ for all the cases). The $\mathrm{m} / \mathrm{z}$ range was chosen according to the mass of the sample. The acquired data was processed using the Bruker software FlexAnalysis 3.3. As MALDI matrix, a solution of 2,5-dihydroxybenzoic acid (DHB) $(5-10 \mathrm{mg} / \mathrm{mL})$ in aqueous TFA $(0.1 \%)$ containing $30 \%$ of $\mathrm{CH}_{3} \mathrm{CN}$ and $0.005 \% \mathrm{NaCl}$ was employed.

Alkyne linker synthesis. 1,2-Dipalmitoyl-sn-glycerol was activated as $N$-hydroxysuccinimidyl carbonate as previously described..$^{10}$ To a cooled $\left(0^{\circ} \mathrm{C}\right)$ solution of $\mathrm{N}$-hydroxysuccinimidyl activated 1,2-dipalmitoyl-sn-glycerol $(70 \mathrm{mg}, 0.099 \mathrm{mmol})$ in $\mathrm{CH}_{2} \mathrm{Cl}_{2}(5 \mathrm{~mL})$, propargyl amine $(7.5 \mu \mathrm{L}, 0.118 \mathrm{mmol})$ and triethylamine $(200 \mu \mathrm{L})$ were added. The solution was stirred at room temperature overnight. The reaction mixture was partitioned between $\mathrm{CH}_{2} \mathrm{Cl}_{2}$ and water. The aqueous phase was extracted with $\mathrm{CH}_{2} \mathrm{Cl}_{2}(3 \mathrm{x})$ and the combined organic layers were washed with saturated aqueous $\mathrm{NaCl}$ solution, dried over anhydrous $\mathrm{Na}_{2} \mathrm{SO}_{4}$, filtered and concentrated to dryness. The crude product was purified by flash column chromatography (Hexane: EtOAc, 1:1 to $0: 1)$ and the desired product was obtained as a white solid (57 mg, $88 \%) .{ }^{1} \mathrm{H}$ NMR (500 MHz, CDCl3) $\delta 5.26-5.22(\mathrm{~m}, 1 \mathrm{H}), 5.01$ (bs, $1 \mathrm{H}), 4.28-4.10(\mathrm{~m}, 6 \mathrm{H}), 3.96$ (bs, $2 \mathrm{H}), 2.35-2.28(\mathrm{~m}, 4 \mathrm{H})$, $1.62-1.55(\mathrm{~m}, 4 \mathrm{H}), 1.29-1.24(\mathrm{~m}, 48 \mathrm{H}), 0.86(\mathrm{t}, J=6.9 \mathrm{~Hz}$, $6 \mathrm{H}) ; 13 \mathrm{C}$ NMR $(126 \mathrm{MHz}, \mathrm{CDCl} 3) \delta 173.34,172.95,172.01$, $155.31,71.73,69.00,64.97,63.22,62.03,34.19,34.07,34.02$, $31.88,30.84,29.66,29.62,29.59,29.56,29.46,29.44,29.41$, $29.32,29.24,29.21,29.08,29.05,25.39,24.84,24.82,22.65$, 14.08. HRMS calculated for $\mathrm{C}_{39} \mathrm{H}_{71} \mathrm{NNaO}_{6}$ 672.5179, found 672.5165 .

Alkyne functionalized hydrophobic layer on ITO surface. Indium tin oxide (ITO) coated glass slides were cleaned under heating $\left(60^{\circ} \mathrm{C}\right)$ for one hour in basic piranha solution $(40 \mathrm{~mL}$ of $\mathrm{H}_{2} \mathrm{O}, 15 \mathrm{~mL} \mathrm{H}_{2} \mathrm{O}_{2}$ and $15 \mathrm{~mL}$ of $\mathrm{NH}_{3}$ ). The slides were extensively washed with water, dried and incubated with a solution of octadecylphosphonic acid (ODPA) $1 \mathrm{mM}$ in THF at room temperature during 2 hours. The resulting surfaces were annealed at 140 ${ }^{\circ} \mathrm{C}$ for 20 hours. After this time, the slides were washed with $\mathrm{MeOH}$ under sonication to remove any non-covalent bound material. Contact angle for surface modified by ODPA was measured $\theta$ $112 \pm 2^{\circ}$. ODPA modified ITO slides were incubated overnight at room temperature with a solution of alkyne linker $2(1 \mathrm{mM})$ in $\mathrm{CHCl}_{3}$ at room temperature. Slides were dried under a stream of argon and stored at room temperature until use. Contact angle for surface modified with alkyne linker 2 was measured $\theta 102 \pm 3^{\circ}$.

Immobilization of $\mathrm{LacN}_{3}$ on alkyne modified ITO. Serial dilutions of $\mathrm{LacN}_{3}(0.5 \mathrm{mM}, 1 \mathrm{mM}, 2 \mathrm{mM}, 4 \mathrm{mM}, 5 \mathrm{mM}, 8 \mathrm{mM})$ containing $\mathrm{CuSO}_{4}(2.5 \mathrm{mM})$ and ascorbic acid $(12.5 \mathrm{mM})$ were prepared and the solutions $(1 \mu \mathrm{L})$ were spotted on top of alkyne modified ITO. The spots were dried at room temperature and the surface was rinsed with water to remove non-covalent bound materials. Matrix solution was spotted on top, dried at room temperature and analyzed by MALDI-TOF MS.

Enzymatic reactions with $A$. oryzae $\beta$-galactosidase. Two fold dilutions of $A$. oryzae $\beta$-galactosidase enzyme (100, 50, 25, 12.5, $6.25,3.12 \mu \mathrm{g} / \mathrm{mL})$ were incubated with $\mathrm{LacN}_{3}(5 \mathrm{mM})$ in $\mathrm{NaOAc}$ buffer $(50 \mathrm{mM}, \mathrm{pH} 5)$ at $37^{\circ} \mathrm{C}$ for 30 minutes. The enzymatic reactions were heated at $95{ }^{\circ} \mathrm{C}$ for five minutes in order to stop enzymatic reactions. $\mathrm{CuSO}_{4}(2.5 \mathrm{mM})$ and ascorbic acid $(12.5$ $\mathrm{mM}$ ) were added to the solutions and spotted on top of alkyne modified ITO. The spots were dried at room temperature and the surface was rinsed with water to remove non-covalent bound 
materials. Matrix solution was spotted on top, dried at room temperature and analyzed by MALDI-MS.

Enzymatic reactions with $\boldsymbol{E}$. coli $\boldsymbol{\beta}$-galactosidase. Two fold dilutions of $E$. coli $\beta$-galactosidase $(0.170,0.085,0.042,0.021$, $0.005 \mu \mathrm{g} / \mathrm{mL})$ in PBS containing $\mathrm{MgCl}_{2}(1 \mathrm{mM}) \mathrm{pH} 7.4$ were incubated with $\mathrm{LacN}_{3}(5 \mathrm{mM})$ at $37^{\circ} \mathrm{C}$ for 30 minutes. The enzymatic reactions were analyzed as described above.

Measurement of $\beta$-galactosidase activity in $E$. coli (ATCC 25922) extracts. A single colony of E. coli ATCC 25922 was inoculated in $1 \mathrm{~mL}$ of $\mathrm{M} 9$ minimal medium (MM) containing $0.4 \%$ glucose and M9 MM containing $0.4 \%$ lactose. Bacterial cultures were growth at $37^{\circ} \mathrm{C}$ until they reached $\mathrm{OD}_{600 \mathrm{~nm}}=0.9-1.0$. Bacteria were centrifuged at $4000 \times \mathrm{xg}$ for 10 minutes at $4{ }^{\circ} \mathrm{C}$ and pellets were resuspended in buffer $\left(60 \mathrm{mM} \mathrm{Na} 2 \mathrm{HPO}_{4} \cdot 2 \mathrm{H}_{2} \mathrm{O}, 40\right.$ $\left.\mathrm{mM} \mathrm{NaH} \mathrm{PO}_{4}, 10 \mathrm{mM} \mathrm{KCl}, 1 \mathrm{mM} \mathrm{MgSO} 4\right)$. Bacteria were permeabilized with SDS $(0.1 \%)$ and chloroform. Galactosidase assay was performed in $40 \mu \mathrm{L}$ of bacterial extract containing $\mathrm{LacN}_{3}(5$ $\mathrm{mM})$. The solutions were incubated at $37^{\circ} \mathrm{C}$ for 30 minutes. $\mathrm{CuSO}_{4}(2.5 \mathrm{mM})$ and ascorbic acid $(12.5 \mathrm{mM})$ were added to the solutions and spotted on alkyne modified ITO. The spots were dried at room temperature and the surface was rinsed with water. Matrix solution was spotted on top, dried at room temperature and analyzed by MALDI-TOF MS.

Measurement of $\beta$-galactosidase activity in bacterial cultures. A single colony of E. coli ATCC 25922 and S. aureus ATCC 29213 was inoculated in $0.5 \mathrm{~mL}$ of standard Luria Bertani (LB) medium containing $5 \mathrm{mM}$ of $\mathrm{LacN}_{3}$. The bacterial cultures were incubated at $37^{\circ} \mathrm{C}$, aliquots were taken at different time points and $\mathrm{OD}_{600 \mathrm{~nm}}$ was measured. $\mathrm{CuSO}_{4}(2.5 \mathrm{mM})$ and ascorbic acid $(12.5$ $\mathrm{mM}$ ) were added to the solutions and spotted on top of alkyne modified ITO. The spots were dried at room temperature and the surface was rinsed with water. Matrix solution was spotted on top, dried at room temperature and analyzed by MALDI-TOF MS.

MIC determination. E. coli ATCC 25922 was inoculated in Luria Bertani (LB) medium containing $5 \mathrm{mM}$ of $\mathrm{LacN}_{3}$ and two fold dilutions of ampicillin antibiotic $(64$ to $0 \mu \mathrm{g} / \mathrm{mL})$. The bacterial cultures were incubated for 18 hours at $37^{\circ} \mathrm{C} . \mathrm{CuSO}_{4}(2.5$ $\mathrm{mM})$ and ascorbic acid $(12.5 \mathrm{mM})$ were added to the solutions and spotted on top of alkyne modified ITO. The spots were dried at room temperature and the surface was rinsed with water. Matrix solution was spotted on top, dried at room temperature and analyzed by MALDI-TOF MS.

\section{RESULTS AND DISCUSSION}

Sample plate preparation. ITO slides were functionalized with a hydrophobic self-assembled monolayer (SAM) of octadecylphosphonic acid (ODPA). ${ }^{29}$ This hydrophobic SAM was then employed for the non-covalent and oriented intercalation of the alkyne functionalized bidentate 1,2-sn-dipalmitoyl glycerol. We have previously shown that the non-covalent immobilization via hydrophobic interactions resists repeated washing cycles, provides a tuneable surface for immobilizing a variety of substrates and the covalent ligand-lipid conjugates generated on the surface are easily ionized and detected by MALDI-TOF MS. ${ }^{10}$ (Figure 1) Commercially available ITO covered glass slides were incubated with ODPA solution (SI, Figure S1) and the resulting surface was annealed at high temperature $\left(140{ }^{\circ} \mathrm{C}\right)$ in order to promote the formation of highly stable covalent bonds. After annealing, the wettability of the ODPA modified surface was analyzed by contact angle measurements. ODPA SAMs on ITO showed an important increase in water contact angle measurement, $\left(\theta 112 \pm 2^{\circ}\right.$ for ODPA-ITO) compared to bare ITO $\left(\theta 42^{\circ}\right)$ which is in agreement with previously reported values for this surface modifi- cation. $^{30}$ 1,2-sn-Dipalmitoyl glycerol $\mathbf{1}$ was activated as $\mathrm{N}$ hydroxysuccinimide carbonate and reacted with propargyl amine to produce the alkyne carbamate linker $\mathbf{2}$ in high yield (Scheme 1). ODPA-ITO slides were incubated with a solution of alkyne linker $\mathbf{2}$ to generate a hydrophobic bilayer with terminal alkyne reactive functionality. After immobilization of linker 2 a decrease of $10^{\circ}$ in water contact angle was observed ( $\theta 102 \pm 3^{\circ}$ for alkyne-ITO) indicating a change in the surface. The decrease in hydrophobicity could be explained by the presence of alkyne and carbamate functions which are more polarizable than terminal methyl groups from the ODPA SAM. The immobilization of linker $\mathbf{2}$ on ODPA hydrophobic monolayer was validated by MALDI-TOF MS after matrix deposition. A clean spectra with a signal at $\mathrm{m} / \mathrm{z} 672.9$ corresponding to the molecular mass of linker $2[\mathrm{M}+\mathrm{Na}]^{+}$was obtained (SI, Figure S1).

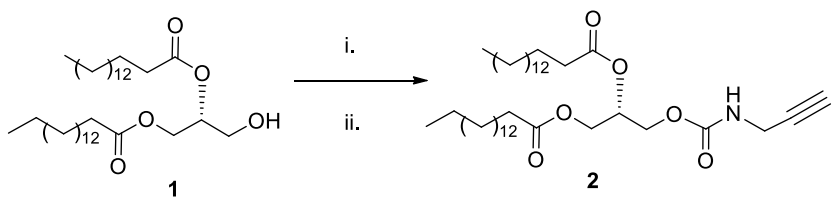

SCHEME 1. Reagents and conditions: i. DSC, $\mathrm{Et}_{3} \mathrm{~N}, \mathrm{CH}_{2} \mathrm{Cl}_{2}, 0^{\circ} \mathrm{C}$ to RT, ii. Propargyl amine, $\mathrm{Et}_{3} \mathrm{~N}, \mathrm{CH}_{2} \mathrm{Cl}_{2}$, RT.

Immobilization of 2-azidoethyl lactose on alkyne ITO. The 2-azidoethyl lactose probe $\left(\mathbf{L a c N}_{3}\right)$ was prepared from peracetylated lactose in three steps with high purity and good overall yield following published procedures. ${ }^{28}$ The immobilization of $\mathrm{LacN}_{3}$ on alkyne modified ITO via CuAAC reaction was then studied employing $\mathrm{CuSO}_{4} \cdot 5 \mathrm{H}_{2} \mathrm{O}$ as copper source and $\mathrm{L}$-ascorbic acid as reductive reagent to generate $\mathrm{Cu}(\mathrm{I})$ species. ${ }^{27}$ The different reagents were mixed with $\mathrm{LacN}_{3}$, spotted on the alkyne modified ITO and dried at room temperature. The hydrophobic bilayer is stable under aqueous conditions and therefore, the surface could be rinsed with water in order to remove salts and the excess of reagents/catalyst employed. After matrix deposition, we were able to record a clean spectra showing a signal corresponding to the sodium adduct from lactose probe conjugated to the alkyne lipid linker $2\left([\mathrm{Lac}+\mathrm{Na}]^{+}, m / z \quad 1084.5 \mathrm{Da}\right)$ along with unreacted background linker $2(\mathrm{~m} / \mathrm{z} 672.9)$ by MALDI-TOF MS (Figure 2A). As the trapping reaction of the light-weight $\mathrm{LacN}_{3}$ probe $(\mathrm{m} / \mathrm{z}$ $411.1 \mathrm{Da})$ with the surface results in the formation of a conjugate with a mass of $m / z$ 1066.5 Da no interference from matrix ions is observed further highlighting the advantage of the onchip conjugation particularly for the analysis of small molecules. Increasing concentrations of $\mathrm{LacN}_{3}$ were spotted in the presence of L-ascorbic acid and $\mathrm{CuSO}_{4} \cdot 5 \mathrm{H}_{2} \mathrm{O}$ on alkyne modified ITO slides. The spots were dried at room temperature and after rinsing with water the surface was analyzed by MALDITOF MS. The efficacy of the immobilization was defined as the ratio of the signal intensity for the sodicated lactose peak $[\mathrm{Lac}+\mathrm{Na}]^{+}$to the sum peak intensities of unreacted linker (2) and lactose, for which we assumed a constant concentration over the hydrophobic surface (Figure 2B). As seen in Figure $2 \mathrm{~B}$, the immobilization of the lactose probe increased proportionally with the spotted quantity and reached a maximum at around 7-8 nmol of $\mathrm{LacN}_{3} /$ spot. Immobilization via $\mathrm{CuAAC}$ on alkyne modified ITO was highly efficient and provided peaks for the sodicated lactose ion witha signal to noise ratio 
greater than 20 down to a level of 5 picomol of lactose ligand. (SI, Figure S2).

The attachment of carbohydrates to functionalized surfaces provides a simple method for the in situ clean-up of the desired analyte. $\mathrm{LacN}_{3}$ dissolved in LB broth, a complex media commonly employed for bacterial culture, was spotted on alkyne ITO in the presence of copper salts and ascorbic acid. The spots were dried and analyzed before and after aqueous washing (SI, Figure S3). After the aqueous washing clean MALDI-TOF spectra were obtained for the immobilized lactose with good signal intensity, while the omission of the clean-up step resulted in low quality spectra with strong ion suppression and spectral overlap from background ions from the complex matrix.

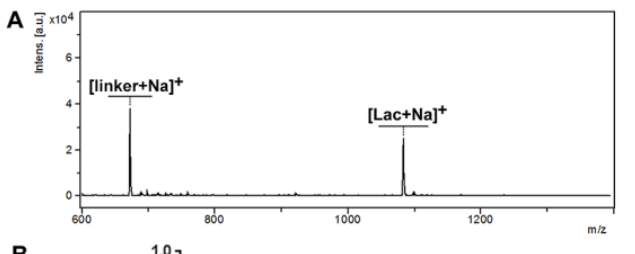

B

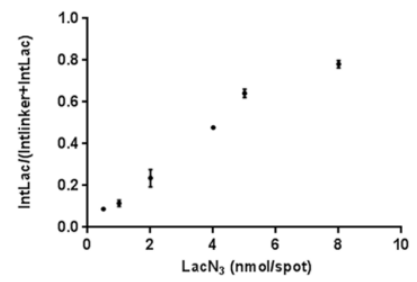

Figure 2. A. MALDI-TOF spectra after immobilization of $\mathrm{LacN}_{3}$ ( $4 \mathrm{nmol}$ ) on alkyne modified ITO in the presence of $\mathrm{Cu}$ (I) species. B. Immobilization of increasing amounts of $\mathrm{LacN}_{3}$ on alkyne modified ITO. Each data point represents duplicate immobilization experiments.

$\boldsymbol{\beta}$-galactosidase activity measurements. Next, we applied the surface based $\mathrm{LacN}_{3}$ probe capture to detect glycosidase activity. The $\beta$-galactosidase enzyme cleaves the glycosidic bond between the two sugars units producing azidoethyl glucose $\left(\mathrm{GlcN}_{3}\right)$ and free reducing galactose (Figure 1A). Covalent capture and analysis of remaining unreacted $\mathrm{LacN}_{3}$ and $\mathrm{GlcN}_{3}$ product would provide a ratio between the starting material and product peaks as a relative measure of glycosidase activity. We verified the quantification method To validate the quantification of probe hydrolysis by measuring mass spectrometry that the measurement our strategy would provide the correct quantification for mixtures of $\mathrm{GlcN}_{3}$ and $\mathrm{LacN}_{3}$, we immobilized defined mixtures of both analytes at a constant concentration under optimized conditions. MALDI-TOF mass spectra were obtained for all glycan mixtures presenting peaks corresponding to the lactose probe $[\mathrm{Lac}+\mathrm{Na}]^{+}$at $\mathrm{m} / z, 1084.5$ $\mathrm{Da}$ and to glucose probe $[\mathrm{Glc}+\mathrm{Na}]^{+}$at $\mathrm{m} / z$ 921.5 Da. The amount of $\mathrm{LacN}_{3}$ in the mixtures was accurately quantified by the ratio $\mathrm{i}$ of the lactose peak intensity to the sum of lactose and glucose peaks intensities (SI, Figure S4).

We studied the activity of two commercially available $\beta$ galactosidase enzymes from A. oryzae and from E. coli. The enzymatic hydrolysis of $\mathrm{LacN}_{3}$ was carried out at two fold serial dilutions of the two $\beta$-galactosidases for 30 minutes at $37^{\circ} \mathrm{C}$. The enzymatic reactions were stopped by heating to 95 ${ }^{\circ} \mathrm{C}$ and probe ratios analyzed by MALDI-TOF MS after spotting the reaction crude onto alkyne modified ITO and rinsing with water. Clean spectra were obtained for all enzyme concentrations presenting only peaks corresponding to the lactose probe $[\mathrm{Lac}+\mathrm{Na}]^{+}$at $\mathrm{m} / \mathrm{z}$ 1084.5 $\mathrm{Da}$ and to the hydrolysis product $[\mathrm{Glc}+\mathrm{Na}]^{+}$at $\mathrm{m} / z$ 921.5 Da (Figure 3A). The degree of hydrolysis was defined as the ratio of the signal intensity of the sodicated glucose $t$ peak to the sum of intensities for remaining sodicated lactose and glucose ions. The degree of hydrolysis was plotted against the concentration of enzyme employed in each reaction. For $\beta$-galactosidase from $A$. oryzae (Figure $3 \mathrm{~B}$ ) this representation follows a nonlinear regression curve with conversion ratios reaching saturation at enzyme concentration of $100 \mu \mathrm{g} / \mathrm{mL}$. On the other hand, $\beta$ galactosidase from $E$. coli (Figure $3 \mathrm{C}$ ) showed a linear relationship for the enzyme concentrations assayed. Importantly, both enzymes showed considerable activity and conversion after 30 minutes already at low enzyme concentrations.

A

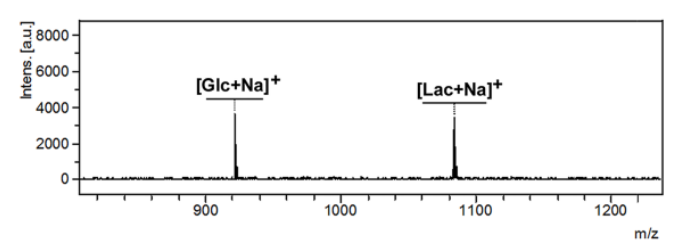

B
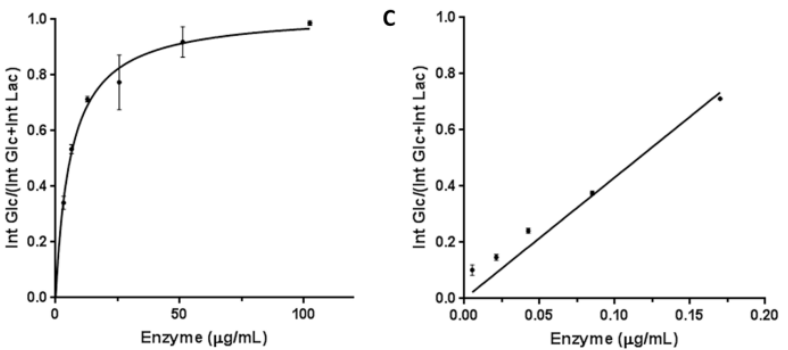

Figure 3. A. MALDI-TOF spectra after incubation with $\beta$ galactosidase from A. oryzae $(6.25 \mu \mathrm{g} / \mathrm{mL})$. B. Incubation with increasing concentrations of $\beta$-galactosidase from $A$. oryzae. $\mathbf{C}$. Incubation with increasing concentrations of $\beta$-galactosidase from E. coli. Each data point represents the average and standard deviation from three independent MALDI-TOF measurements.

$\beta$-Galactosidase activity in bacterial lysates. The measurement of $\beta$-galactosidase activity is a good marker for coliform bacteria such as E. coli or Klebsiella without significant interference from non-coliform bacteria. ${ }^{31} E$. coli $\beta$-galactosidase is a homotetrameric protein encoded by the lac $Z$ gene which is part of the genetically inducible lac operon. ${ }^{32}$ This enzyme plays a key role in central carbon metabolism of the bacteria and its expression in vivo is related to the availability of lactose in the media. As many other bacteria, E. coli prefers glucose as a carbon source, which supports higher growth rates than other carbohydrates. Nevertheless, the bacterial growth in the presence of glucose leads to a reduced catabolic expression of glycosyl hydrolases. ${ }^{33}$ We applied the alkyne modified surface to measure the bacterial $\beta$-galactosidase activity in $E$. coli ATCC 25922 extracts cultured under two different growth conditions, in minimal medium (MM) with glucose as the sole carbon source that would inhibit $\beta$-galactosidase expression and in a MM containing lactose, which induces $\beta$ galactosidase expression. Bacteria were grown at $37{ }^{\circ} \mathrm{C}$, permeabilized with a mixture of SDS and chloroform and cell extracts were incubated with $\mathrm{LacN}_{3}$ at $37^{\circ} \mathrm{C}$ for 30 minutes. $\mathrm{LacN}_{3}$ probe and hydrolysis product were captured from the crude cell extracts on the surface, analyzed by MALDI-TOF MS and the degree of hydrolysis determined as described above. As the immobilization of analytes is completed within 
a few minutes, we can assume that product to probe ratios are largely the same as in solution. As shown in Figure 4, important induction of $\beta$-galactosidase expression was observed in the bacterial extracts after growth in MM-lactose while in MM-glucose cultures only residual hydrolytic activity could be detected.

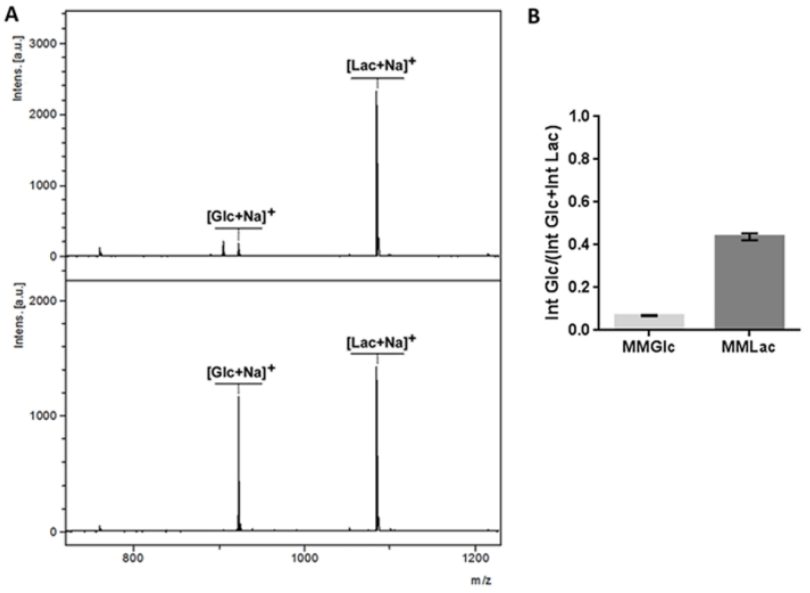

Figure 4. A. MALDI-TOF spectra after incubation with $E$. coli cell extracts growth in minimal medium (MM) containing as carbon source $0.4 \%$ glucose, (MMGlc, up) and $0.4 \%$ lactose (MMLac, down). B. Quantification of $\beta$-galactosidase activity in E. coli bacterial lysates growth in MMGlc and MMLac. Each histogram represents duplicate immobilization experiments.

Detection of $\boldsymbol{\beta}$-galactosidase activity as probe for bacterial growth. As hypothesized in the introduction, we intended to relate detection of a particular bacterial enzymatic activity to bacterial growth, and perhaps even aid in their identification or functional classification. To this end, we monitored $\beta$ galactosidase activity at different time points in growing cultures of two bacteria, namely gram negative E. coli ATCC 25922 and gram positive $S$. aureus ATCC $29213 .{ }^{34}$ The detection of enzymatic activity in vivo via the MALDI-TOF capture method avoids possible interference of growth media and supplements on commonly employed colorimetric methods. In addition, as the probe is cell permeable, this method allows the detection of bacterial $\beta$-galactosidase activity directly in the supernatant of the bacterial culture without prior preparation of bacterial extracts. Bacteria were cultured in LB medium supplemented with $\mathrm{LacN}_{3}$ and the hydrolysis of $\mathrm{LacN}_{3}$ was monitored by MALDI-TOF MS at different time points (Figure 5). The concentration of $\mathrm{LacN}_{3}$ in the culture supernatants was determined by MALDI-TOF MS as described above.. In both cultures, a decrease for the initial $\mathrm{LacN}_{3}$ probe was detected (Figure 5, black line) that corresponded to an increase in the bacterial density measured as the absorbance at $600 \mathrm{~nm}$ $\left(\mathrm{OD}_{600 \mathrm{~nm}}\right)$ (Figure 5, dotted line).

To discard any potential source of non-bacterial $\mathrm{LacN}_{3}$ hydrolysis, a control experiment was performed with E. coli DH5 $\alpha$ a strain that is not able to express functional $\beta$ galactosidase enzyme as it contains a partial deletion of the galactosidase gene. A culture of $E$. coli $\mathrm{DH} 5 \alpha$ in LB medium supplemented with $\mathrm{LacN}_{3}$ was grown at $37{ }^{\circ} \mathrm{C}$ overnight and the supernatant of the culture was analyzed by MALDI-TOF. Only the peak corresponding to the undigested lactose probe was detected (SI, Figure S5).

MIC determination. The minimal inhibitory concentration (MIC) is defined as the lowest concentration of an antibiotic that inhibits the visible growth of bacteria cultured under standardized conditions. The accurate determination of MIC is fundamental in clinical microbiology laboratories to establish the best antibiotic treatment option and is determined generally by broth or agar dilution tests. ${ }^{35} \beta$-galactosidase activity measurements on alkyne ITO were applied for the determination of MIC. Cultures of E. coli ATCC 25922 (ampicillin MIC $=4 \mu \mathrm{g} / \mathrm{mL}$ ) supplemented with $\mathrm{LacN}_{3}$ were incubated overnight at $37{ }^{\circ} \mathrm{C}$ in the presence of increasing amounts of the antibiotic ampicillin ( 0 to $64 \mu \mathrm{g} / \mathrm{mL}$ ). The $\beta$-galactosidase activity in the culture supernatants was analyzed by MALDITOF MS (see SI, Figure S6) and product to $\mathrm{LacN}_{3}$ probe ratios plotted against growing ampicillin concentrations (Figure 6). The data was adjusted to Gompertz equation ${ }^{36}$ and MIC was calculated to be $4.24 \mu \mathrm{g} / \mathrm{mL}$ which is in the range for this antibiotic. $^{37}$

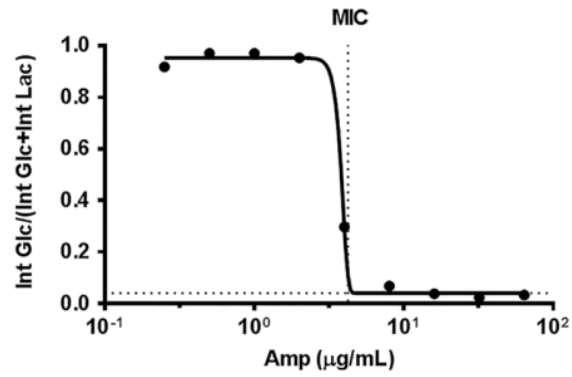

Figure 6. MIC determination in ATCC 25922 overnight cultures in the presence of increasing amounts of ampicillin antibiotic.

\section{CONCLUSIONS}

We have developed a MALDI active surface for the bioorthogonal capture via $\mathrm{CuAAc}$ of azide functionalized carbohydrates from complex media. The activity of $\beta$ galactosidase enzyme was measured efficiently by comparing the signals strength ratios for product and initial probe. This in situ clean-up method allowed the analysis of glycosidase activity directly in bacterial cultures without the requirement of previous extraction of enzymes. ${ }^{14}$ This method was further employed to determine the antibiotic susceptibility of bacterial cultures towards a model antibiotic. The method makes use of MALDI-TOF mass spectrometers which have found wide acceptance in clinical microbiology laboratories for bacterial identification and produces functional results even under conditions where optical methods could suffer from media interference. We are currently preparing new probes for a multiplexed assay to measure the activity of various human health related bacterial glycosidases. 
A

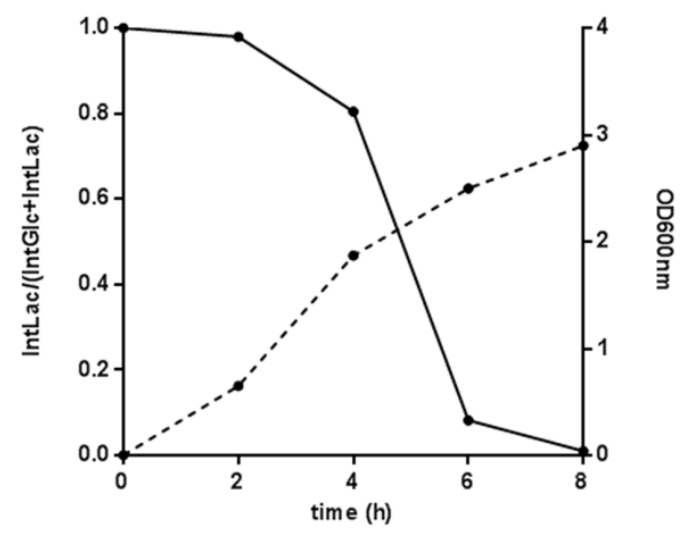

B

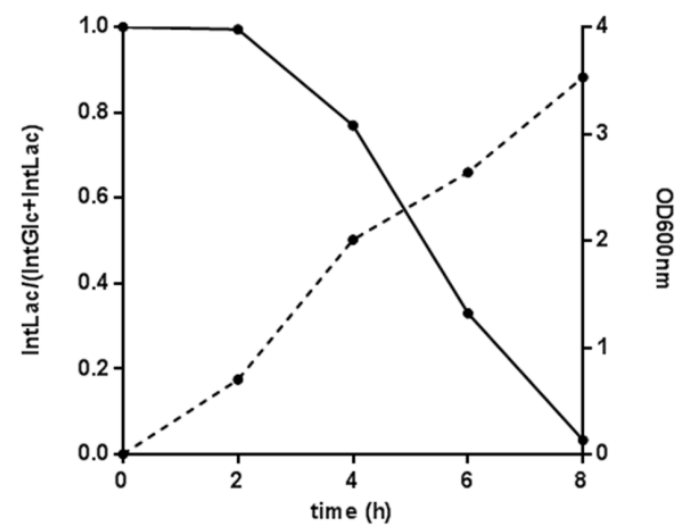

Figure 5. Bacterial cultures of E. coli ATCC 25922 (A) and S. aureus ATCC 29213 (B). Bacterial growth is monitored by measurements of $\mathrm{OD}_{600 \mathrm{~nm}}$ (dotted line) and by $\mathrm{LacN}_{3}$ hydrolysis at different fermentation times (black line).

\section{ASSOCIATED CONTENT}

\section{Supporting Information}

The Supporting Information is available free of charge on the ACS Publications website.

NMR spectra of linker $\mathbf{2}$ and supporting figures (PDF)

\section{AUTHOR INFORMATION}

\section{Corresponding Author}

* Niels-Christian Reichardt nreichardt@ cicbiomagune.es

\section{ORCID}

Niels-Christian Reichardt 0000-0002-9092-7023

Sonia Serna 0000-0002-2085-4412

\section{ACKNOWLEDGMENT}

We acknowledge funding from the Spanish Ministry of Economy and Competiveness (MINECO, CTQ2014-58779-R grant) and the Basque Government (Etortek grants 2015, 2016, 2017)

\section{REFERENCES}

(1) Kaoutari, A. El; Armougom, F.; Gordon, J. I.; Raoult, D.; Henrissat, B. Nat. Rev. Microbiol. 2013, 11 (7), 497-504.

(2) Law, J. W. F.; Mutalib, N. S. A.; Chan, K. G.; Lee, L. H. Front. Microbiol. 2014, 5 (DEC), 1-19.

(3) Jung, J. S.; Eberl, T.; Sparbier, K.; Lange, C.; Kostrzewa, M.; Schubert, S.; Wieser, A. Eur. J. Clin. Microbiol. Infect. Dis. 2014, 33 (6), 949-955. Dellinger RP, Levy MM, Rhodes A, Annane D, Gerlach H, Opal SM, Sevransky JE, Sprung CL, Douglas IS, Jaeschke R, Osborn TM, Nunnally ME, Townsend SR, Reinhart K, Kleinpell RM, Angus DC, Deutschman CS, Machado FR, Rubenfeld GD, Webb SA, Beale RJ, Vincent JL, M. R. Crit. Care Med. 2013, 41 (2), 580-637.

(5) Jorgensen, J. H.; Ferraro, M. J. Clin. Infect. Dis. 2009, 49 (11), 1749-1755.

(6) Pelisek, J.; Armeanu, S.; Nikol, S. J. Vasc. Res. 2000, 37 (6), 585-593.

(7) Gray, C. J.; Weissenborn, M. J.; Eyers, C. E.; Flitsch, S. L. Chem. Soc. Rev. 2013, 42 (15), 6378.

(8) Beloqui, A.; Sanchez-Ruiz, A.; Martin-Lomas, M.; Reichardt, N.-C. Chem. Commun. 2012, 48 (11), 1701-1703.

(9) Northen, T. R.; Lee, J.; Hoang, L.; Raymond, J.; Hwang, D.; Yannone, S. M.; Wong, C.; Siuzdak, G. Proc. Natl. Acad. Sci. U. S. A. 2008, 105 (10), 3678-3683.

(10) Beloqui, A.; Calvo, J.; Serna, S.; Yan, S.; Wilson, I. B. H.; Martin-Lomas, M.; Reichardt, N. C. Angew. Chemie - Int. Ed.

2013, 52 (29), 7477-7481.

$\mathrm{Su}$ J.; Mrksich, M. Angew. Chem. Int. Ed. Engl. 2002, 41 (24), 4715-4718.

Chang, S. H.; Han, J. L.; Tseng, S. Y.; Lee, H. Y.; Lin, C. W.; Lin, Y. C.; Jeng, W. Y.; Wang, A. H. J.; Wu, C. Y.; Wong, C. H. J. Am. Chem. Soc. 2010, 132 (38), 13371-13380.

Houseman, B. T.; Mrksich, M. Angew. Chemie Int. Ed. 1999, 38 (6), 782-785.

Reindl, W.; Deng, K.; Gladden, J. M.; Cheng, G.; Wong, A.; Singer, S. W.; Singh, S.; Lee, J.-C.; Yao, C.-H.; Hazen, T. C.; Singh, A. K.; Simmons, B. A.; Adams, P. D.; Northen, T. R. Energy Environ. Sci. 2011, 4 (8), 2884.

Deng, K.; George, K. W.; Reindl, W.; Keasling, J. D.; Adams, P. D.; Lee, T. S.; Singh, A. K.; Northen, T. R. Rapid Commun. Mass Spectrom. 2012, 26 (6), 611-615.

Yang, H.; Chan, A. L.; Lavallo, V.; Cheng, Q. ACS Appl. Mater Interfaces 2016, 8 (4), 2872-2878.

Min, D. H.; Yeo, W. S.; Mrksich, M. Anal. Chem. 2004, 76 (14), 3923-3929.

Lin, P. C.; Ueng, S. H.; Tseng, M. C.; Ko, J. L.; Huang, K. T.; Yu, S. C.; Adak, A. K.; Chen, Y. J.; Lin, C. C. Angew. ChemieInt. Ed. 2006, 45 (26), 4286-4290.

Maalouli, N.; Barras, A.; Siriwardena, A.; Bouazaoui, M.; Boukherroub, R.; Szunerits, S. Analyst 2013, 138 (3), 805-812.

Sun, X.-L.; Stabler, C. L.; Cazalis, C. S.; Chaikof, E. L. Bioconjug. Chem. 2006, 17, 52-57.

Harju, M.; Kallioinen, H.; Tossavainen, O. Int. Dairy J. 2012, 22 (2), 104-109.

Naylor, L. H. Biochem. Pharmacol. 1999, 58 (5), 749-757.

Tiwari, V. K.; Mishra, B. B.; Mishra, K. B.; Mishra, N.; Singh, A. S.; Chen, X. Chem. Rev. 2016, 116 (5), 3086-3240.

Carvalho, I.; Andrade, P.; Campo, V. L.; Guedes, P. M. M.; Sesti-Costa, R.; Silva, J. S.; Schenkman, S.; Dedola, S.; Hill, L.; Rejzek, M.; Nepogodiev, S. A.; Field, R. A. Bioorganic Med. Chem. 2010, 18 (7), 2412-2427.

Soomro, Z. H.; Cecioni, S.; Blanchard, H.; Praly, J.-P.; Imberty, A.; Vidal, S.; Matthews, S. E. Org. Biomol. Chem. 2011, 9 (19), 6587.

Bryan, M. C.; Fazio, F.; Lee, H. K.; Huang, C. Y.; Chang, A. Best, M. D.; Calarese, D. A.; Blixt, O.; Paulson, J. C.; Burton, D.; Wilson, I. A.; Wong, C. H. J. Am. Chem. Soc. 2004, 126 (28), 8640-8641.

Zilio, C.; Bernardi, A.; Palmioli, A.; Salina, M.; Tagliabue, G.; Buscaglia, M.; Consonni, R.; Chiari, M. Sensors Actuators B. Chem. 2015, 215, 412-420.

Chernyak, A. Y.; Sharma, G. V. M.; Kononov, L. O.; Krishna, P. R.; Levinsky, A. B.; Kochetkov, N. K.; Rao, A. V. R. Carbohydr. Res. 1992, 223, 303-309.

\section{Jo, K.; Yang, H. J. Electroanal. Chem. 2014, 712, 8-13.}

Chen, X.; Luais, E.; Darwish, N.; Ciampi, S.; Thordarson, P.; Gooding, J. J. Langmuir 2012, 28 (25), 9487-9495.

Fiksdal, L.; Tryland, I. Curr. Opin. Biotechnol. 2008, 19 (3), 289-294. 
Nature 1994, 369 (6483), 761-766.

(33)

Inada T. Kimata, K. Aiba, H.

$$
301 .
$$

(34) Rosey, E. L.; Oskouian, B.; Stewart, G. C. J. Bacteriol. 1991, 173 (19), 5992-5998.

(35) Wiegand, I.; Hilpert, K.; Hancock, R. E. W. Nat. Protoc. 2008,
3 (2), 163-175.

(36)

Lambert, R. J. W.; Pearson, J. J. Appl. Microbiol. 2000, 88, 784-790.

(37) European Committee for Antimicrobial Susceptibility Testing, E. Clin. Microbiol. Infect. 2003, 9 (8), ix-xv.

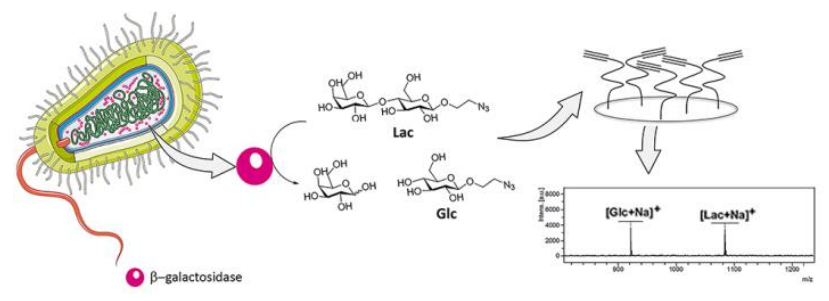

